\title{
DETERMINATION OF CENTRAL FORAGING STRATIEGIES AND LOCATION OF BEAVER (CASTOR CANADENSIS) IN Grand Teton National PaRK
}

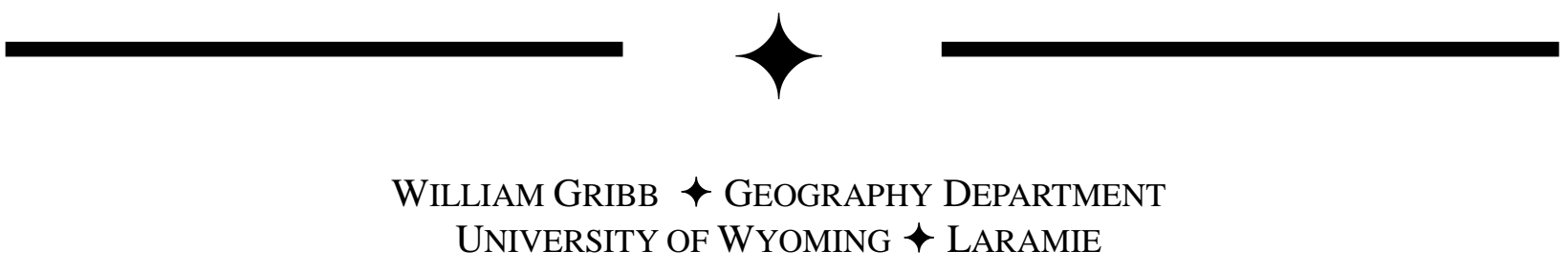

\section{$\uparrow \quad$ AbSTRACT}

Beavers (Castor Canadensis) are an indicator species of an ecosystems health. To utilize them as an indicator it is imperative to know their location and their foraging and movement patterns. This project examined the foraging characteristics of eight colonies in Grand Teton National Park and completed an aerial survey of their distribution. Overall, the beavers, on average, foraged an area of 1.01ha and traversed $381.1 \mathrm{~m}$ collecting food, mainly willows (Salix spp.) with some alder (Alnus incana) and aspen (Populus tremuloides). The aerial survey found 22 active caches distributed over Grand Teton National Park. This is a decrease of 52\% from the previous survey of the same area completed in 2006 (46). Changes in back water channels and ponds could be a major cause of the decline.

\section{$\uparrow \quad$ INTRODUCTION}

The health of an ecosystem is not a subjective guess; a number of different types of indicators are employed to provide objective information that can be evaluated to indicate the condition of the environment. One such indicator is the condition of the beaver (Castor canadensis) population (Naiman, Mellillo and Hobbie, 1986). Knowledge of their distribution, the quality of their habitat, foraging patterns, and movement are critical aspects to knowing the health of the ecosystem. Unfortunately, little is known of riverine beaver foraging and movement. A number of studies have been completed in an attempt to determine the beaver's central foraging strategies, but almost all of these studies have focused on pond, lake, or reservoir beaver activities (McGinley and Whitham, 1985; Johnston and Naiman, 1990; Nolet, Hoekstra and Ottenheim et al., 1994; and Raffel, et al., 2009). Most river research has focused on the reintroduction of the beaver along major rivers in Europe and their subsequent impacts (Fustec et al., 2001). A study by Breck, Wilson, and Anderson (2001) did investigate riverine beavers, but concentrated on the impact of flow regulation on beaver demographic response and had some information on foraging behavior, but nothing in detail. The early work by Collins (1976) and subsequent research by Gribb and Harlow (2006) provides a foundation upon which to examine in more detail the characteristics of beaver distribution and foraging along the Snake River in Grand Teton National Park (GTNP). The Snake River dominates the riparian ecosystem of GTNP and beavers are a critical component of that ecosystem. Thus, by gaining knowledge of the beaver's condition it is possible to know the health of the ecosystem.

In conjunction with beaver distribution and foraging is their pattern of establishing territories. This knowledge is critical to understanding colony distribution and cohesion (Fryxell, 2001). Studies in the United States (Van Deelen and Pletscher, 1996; Bloomquist and Nielsen, 2008) and Europe (Fustec, et al., 2001) provide a better understanding of the movement of subadults and the development of new colonies. Again, the early work of Collins (1976) provides a detailed account of colony size, distribution and territoriality. However, his study reflected conditions 35 years ago and the ecosystem characteristics may have changed. This study seeks 
to expand the overall knowledge of riverine beavers and their foraging characteristics along with an indication of their territoriality along the Snake River, its back waters and tributaries. This will be accomplished by conducting in-depth analysis of the beavers' foraging patterns and completing a systematic aerial survey of beavers in Grand Teton National Park. Select active beaver lodges and the surrounding area will be examined to determine foraging patterns and territorial use. The first aerial survey of GTNP was completed in 2006, and a periodicity of 3-5 years is recommended (Beck and Staley, 2005) so that sub-adults have the ability to leave and establish colonies and these patterns can be identified. By completing the aerial survey, information from two years of surveys allows a more in-depth examination of beaver colony pattern and change.

To address the issues of riverine beaver location, foraging characteristics and territoriality, this project has three main objectives:

1. Determine representative colonies along the Snake River for foraging characteristics.

2. Complete an inventory of plant and tree species that have been browsed by beavers.

3. Complete an aerial survey of beaver locations across Grand Teton National Park.

\section{Study Area}

The study area for this project consists of eight sites in Grand Teton NP for the foraging component of the project and a flight path that consists of aerial reconnaissance along the major rivers/streams in the park. The eight sites in GTNP vary by beaver lodge position: 1 . Snake R. upstream from Jackson Lake; 2. meadow pond adjacent to the Snake R. upstream from Jackson Lake in the Sheffield Creek drainage; 3 . three sites in the Snake R. oxbow; 4. Snake R. at the confluence with Buffalo Fork; 5. a backwater tributary of the Snake R. at the BarBC Ranch; and, 6. Two Ocean Lake (Figure 1.). These sites were selected for two reasons, first they all have active bank lodges and secondly, the habitat surrounding the lodge varies with the physical characteristics of the terrain. The aerial survey of caches focused mainly on the main channels of the Snake R., Buffalo Forks, and Pacific Creek. In addition, the aerial survey searched those portions of the smaller streams that drain into the Snake R. to the Park boundary. For instance, Buffalo Forks was surveyed up-stream to the Park boundary, an area approximately $2.5 \mathrm{kms}$ northeast of the US287 bridge over Buffalo Forks. Similarly, the following rivers/streams were followed to the Park boundary:
Pacific Creek, Arizona Creek and Lizard Creek all draining to the west into the Snake R. or Jackson Lake. The east draining streams were followed until the slope exceeded the limits of beaver habitat, this included Berry Creek, Owl Creek, Moose Creek, and Cottonwood Creek. Back water channels adjacent to and draining into the major rivers and streams were also surveyed.

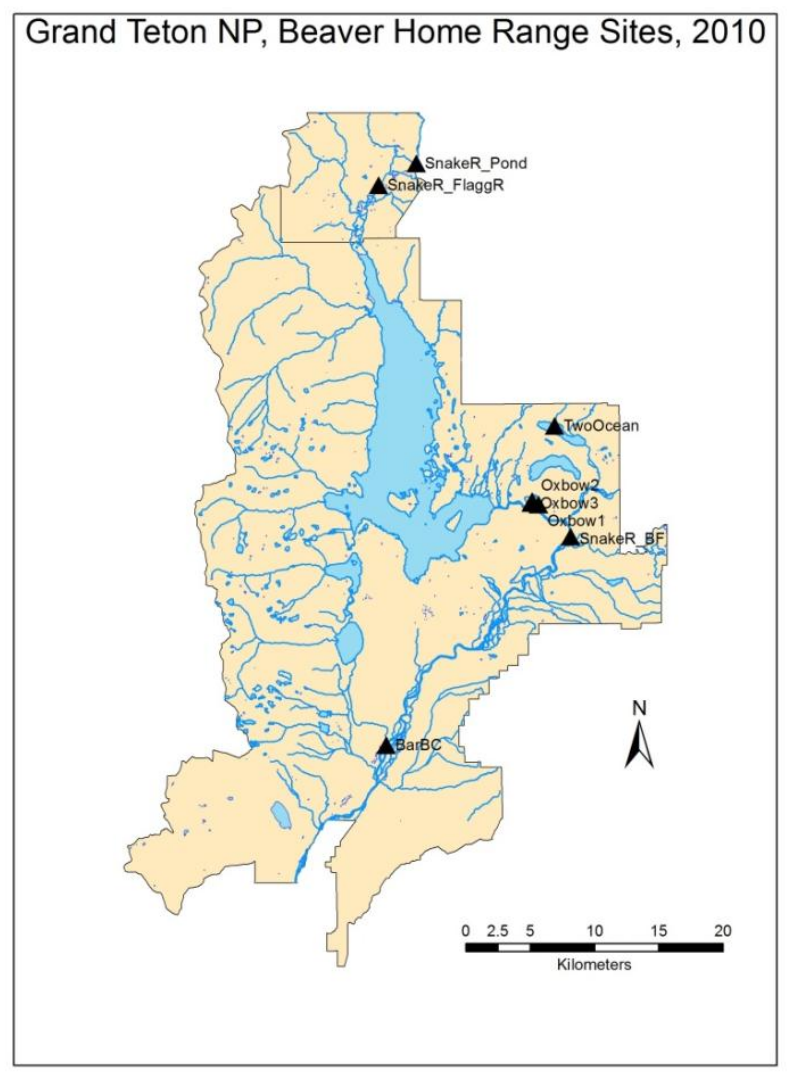

Figure 1. Study area and home range sample sites.

\section{$\downarrow \quad$ METHODS}

Measurements for beaver foraging occurred during two time periods, July 5-9 and Aug. 15-19, 2010. To measure foraging patterns, it is essential to locate the source of the beavers and identify activity areas aligned to the source. The beaver source was identified as any lodge that had recent evidence of beaver activity based on foraging paths, fresh clippings, vegetation cuts, debris piles, tracks, and mud and/or scent mounds. Once a beaver activity area was established, two techniques were used to determine the foraging characteristics of the beaver. The first technique was to measure any activities along a fresh beaver foraging path. A measurement was taken to determine the distance from the lodge to the path at its beginning on the stream bank. Once this was established, all measurements along the path 
were calculated to the stream bank. Every vegetation cluster that had evidence of beaver activity was measured for height, number of stems, stem size, and the stem number and size that were foraged by a beaver. A 1sq.m. area was delineated and all stems were counted and measured within the grid. Three categories of stem size were employed in this survey: small $(<1 \mathrm{~cm})$, medium $(1-2 \mathrm{~cm})$, and large $(>2 \mathrm{~cm})$. In addition, if a tree $(>3 \mathrm{~m}$ in height) had fresh evidence of beaver activity, its diameter was measured.

In the case that there was an active lodge and no pathways, a systematic sample of vegetation clusters by 1 sq.m. grid was taken at 50, 100, 150 meters up-and downstream from the lodge. The same procedure was followed in counting vegetation cluster stems and stems that were foraged. Transects perpendicular to the shoreline were followed onto the land and proceeded every $10 \mathrm{~m}$ until a change in vegetation was encountered or $50 \mathrm{~m}$, the approximate distance beavers stop foraging from water.

The beaver population aerial survey was completed on October 29, 2010. The survey was conducted using a Piper PA-18-150 piloted by Gallatin Flight Service (Belgrade, MT). The aircraft flew between $100-300 \mathrm{~m}$ above surface level, and trying to maintain a constant speed of $130 \mathrm{kph}$. The aerial survey consisted of parallel flights along the major streams in Grand Teton National Park and following the shores of the three major lakes, Jackson, Two Ocean and Emma Matilda, and the minor lakes along the Teton Mountain range including Leigh Lake, Jenny Lake, Bradley and Taggart Lakes (Figure 2). A total of $145 \mathrm{~km}$ of rivers, streams and water bodies were surveyed for food caches. As a food cache was located, gps coordinates were determined and recorded electronically and each site named.

\section{$\uparrow \quad$ PRELIMINARY RESULTS}

A total of eight beaver lodge sites were examined to determine the range and characteristics of beaver foraging. The eight sites varied in their hydrologic environment with three sites along the main channel of the Snake River, three sites situated along backchannels of the Snake R. and two sites on the banks of a pond or lake (Figure 1). In all cases, the bank lodges were active, however, the colony size could not be determined for any of the locations. This analysis will focus on three aspects; the distance from the lodge that is foraged, the characteristics of the browse that is foraged, and the amount of foraging by beavers on browse.

In the Collins' study of 1973-1976 of GTNP beaver ecology, he identified three major vegetation categories for beaver foraging, browse, forbs and graminoids (1976). He found that forbs and graminoids were less than $40 \%$ of the forage by beavers and that it was difficult to determine their area of foraging based on cuttings or litter. Collins had to use fecal analysis to determine the amount of foraging among these two categories. Browse species, on the other hand, were easily identified by the denture cut marks on the stems of these species.

\section{Grand Teton NP Active Beaver Lodges/Dens}

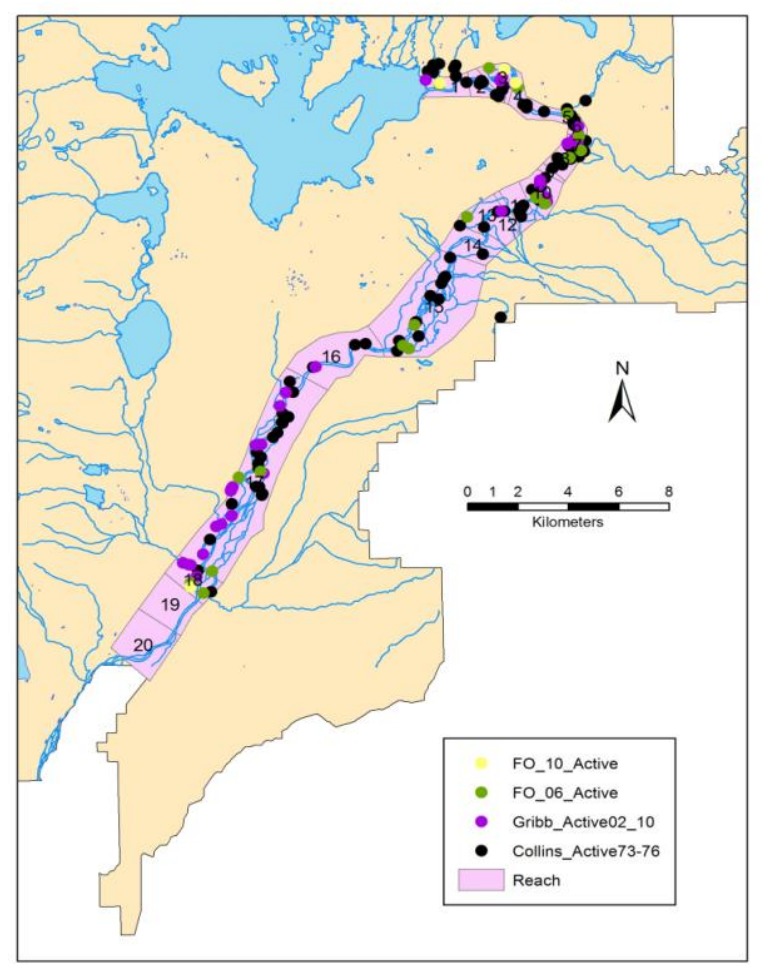

Figure 2. Active Beaver Lodges/Dens by Snake River Reach.

However, foraging patterns changed with the season, summer consumption had a higher percentage of graminoids and forbs, while fall and winter beaver concentrated on browse species (Collins, 1976, pp 105-108).

The distance from the lodge that beavers foraged at the eight sites varied from $2-797 \mathrm{~m}$, with an average of $252 \mathrm{~m}$ in either direction from the lodge (Table 1). The furthest distance was the location at 
the confluence of the Snake River and Buffalo Forks. This location has minimal forage vegetation, but allows access across the Snake R. to sites on the opposite bank. In all of the other sample sites, the maximum distance is in the range from $100-200 \mathrm{~m}$. However, this is biased by the fact that the observations and measurements were obtained in mid-summer before beavers start to cache. In late fall, the distances may increase in the process of caching for winter. In addition, the beavers are not venturing far from water. On average, the beaver is foraging no farther than $18.9 \mathrm{~m}$ from bank edge. This is less than one-third $(60 \mathrm{~m})$ the distances sited for foraging in other habitats (Jenkins, 1980). Again, the shorter distance could be a function of summer diet and no immediate pressure to cache food.

The density and the amount of browse vary between the different sites. However, some basic characteristics can be determined. Overall, an average of 42.6 stems were counted at each bush (Table 1). The number of stems averaged from a low of 28.3 to a high of 79.3. The majority of the bushes were willow (Salix spp.) with small percentages of alder (Alnus incana) (2.6\%) and aspen (Populus tremuloides) $(1.0 \%)$, all of which were less than $3 \mathrm{~m}$ in height. The average height of the bushes was $1.3 \mathrm{~m}$, with only a small variation between $1-1.5 \mathrm{~m}$. The majority of the stem sizes are consistent through the different sites, with stems $<1 \mathrm{~cm}$ accounting for $84.0 \%(35.8 / 42.6)$, while the larger size stems only make up $16 \%, 1-2 \mathrm{~cm}(9.4 \%)$ and $>2 \mathrm{~cm}(5.6 \%)$. None of the sites had trees ( $>3 \mathrm{~m}$ in hgt.), and any large diameter trees were greater than the distances foraged by the beaver.

The amount of foraging on the bushes also varied between sites; however, there were some differences. Forty-six percent of the bush, on average, had been foraged by beavers (Table 2). The Snake R. near Buffalo Forks site experienced almost $64 \%$ of its bushes having evidence of beaver cuts. The Oxbow locations only had slightly more than one-quarter of the bush experience foraging (28.2\%). Thus, the bushes that have evidence of foraging, almost half of the bush will have been cut by beavers. Because of the summer survey period, other aquatic foods and grasses may account for some of the lower percentages of foraging, as identified by Collins (1976).The proportion of the bush stem sizes that had evidence of beaver foraging closely resembles the stem size composition of the bush. The largest majority of the stems cut by beaver are $<1 \mathrm{~cm}$ in diameter $(73.8 \%)$, while the overall proportion of the bush in this diameter size is $84 \%$. It was found that there is no significant difference between the two proportions $(p=.0001)$. Similarly for the other two stem size groups, the $1-2 \mathrm{~cm}$ diameter stems had a $16.9 \%$ foraging rate even though they only account for $9.4 \%$ of the stems, while $>2 \mathrm{~cm}$ experienced a $9.2 \%$ foraging rate and they account for only $5.6 \%$ of the stems.

Relationships between three different components of foraging were explored. The relationship between distance from the lodge and the percent of foraged stems would seem to display a distance decay function, the further from the lodge the less foraging. However, no significant relationship was determined $(\mathrm{r}=.08, p=.001)$. A similar type of relationship could occur between the distance from water and the percent of foraged stems, bushes closer to water could experience more foraging, however, no significant relationship was evident $(\mathrm{r}=.04, p=.005)$. Finally, the relationship

Table 1. Forage Characteristics for Home Range Sites

\begin{tabular}{|c|c|c|c|c|c|c|c|c|}
\hline & \multicolumn{2}{|c|}{ Maximum Dist. } & \multicolumn{5}{|c|}{ Stems } & \multirow[b]{2}{*}{$\mathrm{n}$} \\
\hline & Lodge & Water & $\operatorname{Hgt}(\mathrm{m})$ & $<1 \mathrm{~cm}$ & $(1-2 \mathrm{~cm})$ & $>2 \mathrm{~cm}$ & Total & \\
\hline SnakeR._FlaggRanch & 196.7 & 12.6 & 1.43 & 34.6 & 2.7 & 3.7 & 40.9 & 46 \\
\hline SnakeR._BuffaloFork & 797.0 & 6.5 & 1.18 & 18.4 & 6.8 & 3.1 & 28.3 & 27 \\
\hline SnakeR._BarBCRanch & 108.0 & 14.3 & 1.36 & 34.8 & 1.7 & 0.5 & 36.9 & 65 \\
\hline SnakeR._Pond & 101.8 & 18.9 & 1.01 & 47.9 & 2.8 & 0.0 & 50.7 & 14 \\
\hline SnakeR._Oxbow & 150.0 & 10.5 & 1.15 & 41.6 & 8.1 & 2.7 & 52.4 & 18 \\
\hline Two Ocean Lake & 150.0 & 6.5 & 1.38 & 62.8 & 10.5 & 6.0 & 79.3 & 10 \\
\hline Overall & 250.6 & 11.6 & 1.30 & 35.8 & 4.0 & 2.9 & 42.6 & 180 \\
\hline
\end{tabular}


between the number of stems and the amount or proportion of foraging would indicate that the healthier the bush (the more stems) the higher the likelihood of attracting beavers to forage. Overall, there is a strong relationship between the number of stems and the proportion foraged $(\mathrm{r}=.69, p=.000)$, indicating that the more stems on the bush a higher proportion of them will have evidence of foraging. By using simple regression it was found that there is a $1.45 \%$ increase in foraging with each stem added, $(p=.000)$.

Table 2 provides a comparison of the different home ranges for the eight sites studied. The BarBC site represents a compact area close to the lodge with food close to the waters' edge. Whereas, the Snake River-Buffalo Fork site is elongated and quite a distance from the lodge. Overall, the home range is just over $380 \mathrm{~m}$ and the area of forage is roughly 1 ha. This is considerably different from the measurements of Collins (1976, p 67) in which he observed the home ranges of 10 sites to be $789 \mathrm{~m}$ in length and slightly over $26.2 \mathrm{ha}$ in area.

Table 2. Home Range and Area of Sample Sites

\begin{tabular}{|c|l|c|c|}
\hline ID & \multicolumn{1}{|c|}{ Name } & Length & Area \\
\hline 1 & SnakeR_Pond & 154.0 & 1.10 \\
\hline 2 & SnakeR Flagg Ranch & 235.0 & 0.56 \\
\hline 3 & Two Ocean & 528.0 & 1.27 \\
\hline 4 & Oxbow1 & 565.0 & 1.36 \\
\hline 5 & Oxbow2 & 285.0 & 0.68 \\
\hline 6 & Oxbow3 & 272.0 & 0.65 \\
\hline 7 & SnakeR BuffaloFork & 822.0 & 1.97 \\
\hline 8 & BarBC & 188.0 & 0.45 \\
\hline & & & \\
\hline & & 381.1 & 1.01 \\
\hline
\end{tabular}

The aerial survey of beaver lodges was conducted on 29 October 2010. This is the second aerial survey of Grand Teton National Park, with the first being completed in October, 2006. The October, 2010 survey followed the same transects as the October, 2006 survey, flying a total of approximately $145 \mathrm{~km}$ transecting the Snake River, the major tributaries and adjacent lakes and ponds. A total of 22 beaver caches were identified, located and their position recorded. This represents less than one-half $(47.8 \%)$ of the positions recorded in the 2006 aerial survey (46). And compared to Collins (1976), this represents only $19.6 \%$ of the active lodges/dens that he recorded. Similarly, the field surveys conducted by Gribb and Harlow between 2002-2010 identified 66 active lodges/dens in Grand Teton National Park and this latest aerial survey is only $33.3 \%$ of their findings.

The ability to compare the different surveys provides a base for understanding the changes in beaver population and distribution. Table 3 represents a comparison of the different beaver surveys conducted in GTNP by Collins (1973-1976), Gribb and Harlow (2002-2010), the 2006 aerial survey, and the latest aerial survey in 2010. The comparison is based on the active lodges and dens observed along the Snake River between Jackson Lake Dam and Moose, WY. A study by Nelson (2006-2007) identified 20 river reaches in this portion of the Snake River. In addition, he indexed the river by the number of stream braids, categorizing them from 1 (no braids) to 3 (five braids or more). Thus, a spatial and complexity comparison of the different surveys can be completed.

Collins found active colonies continually through the reaches, while the later studies were more intermittent in finding active beaver lodges and dens. Using a chi-square test, a significant difference can be identified between the different surveys and stream braiding $(p=.000)$, thus demonstrating that there is a significant difference in the spatial arrangement of the active lodges/dens proportional to the survey counts. Figure 2 illustrates the differences between the reaches and the locations of the active lodges/dens and identifies quite clearly Collins' concept that GTNP was almost at beaver carrying capacity during his survey period (1976, pp 35-38). Since that time, however, the number of active colonies has decreased substantially.

Collins (1976, p 36) and Smith, et al (1994) believe that aerial surveys undercount the number of active lodges/dens by $10-20 \%$. This may be true because some river bank lodges and dens may not cache, accessing food sources through the Snake River as long as some portion remains open during the winter. Even increasing the subsequent surveys after Collins by $20 \%$ does not significantly alter the fact that the number of colonies along the Snake River has decreased in the last 35 years by as much as $80 \%$. 
Table 3. Active Beaver Lodges/Dens by Reach

\begin{tabular}{|c|c|c|c|c|c|}
\hline $\begin{array}{l}\text { Reach- } \\
\text { BI }\end{array}$ & Collins & Gribb & $\begin{array}{l}\text { Fly- } \\
\text { Over06 }\end{array}$ & $\begin{array}{l}\text { Fly- } \\
\text { Over10 }\end{array}$ & Length \\
\hline $1-1$ & 2 & 1 & 1 & 1 & 2.22 \\
\hline $2-2$ & 3 & & & & 1.24 \\
\hline $3-1$ & 1 & 3 & 1 & 2 & 1.16 \\
\hline $4-1$ & 4 & & 1 & & 1.73 \\
\hline $5-1$ & & & 1 & & 0.38 \\
\hline $6-1$ & 2 & 1 & & & 0.85 \\
\hline $7-2$ & 1 & & 1 & & 0.26 \\
\hline $8-3$ & 7 & 3 & 2 & & 2.01 \\
\hline $9-1$ & & & & & 0.30 \\
\hline $10-2$ & 3 & 5 & 2 & & 1.67 \\
\hline $11-1$ & 5 & & & & 1.02 \\
\hline $12-1$ & 1 & & & & 0.27 \\
\hline $13-2$ & 1 & 1 & 1 & & 1.64 \\
\hline $14-1$ & 1 & & & & 1.51 \\
\hline $15-2$ & 8 & & 3 & & 6.06 \\
\hline $16-1$ & 2 & 1 & & & 4.05 \\
\hline $17-3$ & 5 & 8 & 3 & & 11.13 \\
\hline $18-3$ & 1 & 5 & 2 & 1 & 1.26 \\
\hline $19-1$ & & & & & 2.12 \\
\hline $20-2$ & & & & & 2.62 \\
\hline Totals & 47 & 28 & 18 & 4 & 43.50 \\
\hline Density & 0.93 & 1.55 & 2.42 & 10.88 & \\
\hline
\end{tabular}

\section{$\downarrow \quad$ MANAGEMENT IMPLICATIONS}

There are three strategies that can be followed that will provide more in-depth insight into the home range and distribution of beavers in Grand Teton National Park to gain more insight into the condition of the ecosystem. First, a more thorough investigation of beaver home range needs to be conducted. This will provide significant information on the area of impact by beaver colonies and the changes in territory by season, a factor not examined in this study. Second, the beaver's foraging characteristics reveal that they are impacting almost $50 \%$ of the bush stems. What was not examined on the same bush was any foraging by other competing species. A number of studies identify the competition between beaver and elk or moose on such browse species as willow (Johnston et al 2007; Olson and Hubert, 1994). It is imperative to understand and monitor the health of willows and other vegetative browse species because of their direct importance. Finally, the beaver population is declining in Grand Teton National Park and the causes have not been studied in detail. A multi-method approach to this issue needs to be addressed to determine the causes of the decline and its implications to the Grand Teton Park ecosystem.

\section{ACKNOWLEDGEMENTS}

This study was completed because of the financial and insightful support from a number of different people and organizations. The Grand Teton National Park personnel have been very supportive of these efforts, specifically Susan Consolo-Murphy, Steven Cain, and Sue O'Ney. The Wyoming Wetlands Society and Luke Bruner have provided both financial and logistical support. However, this study could not have been accomplished without the assistance the number of people providing field survey support, specifically Dr. Hank Harlow, Mary Anne Harlow, and Anne Gribb. And finally, the UW-NPS AMK Ranch research facilities makes spending weeks at a time in the field livable and the stimulating dialogue with other researchers possible.

\section{LITERATURE CITED}

Beck J, Staley D. 2005. Monitoring Protocol for American Beaver (Castor canadensis): Examples from the Bighorn and Black Hills National Forests, USDA Forest Service Region 2 Report.

Bloomquist CK, Nielsen CK. 2010, Demography of unexploited beavers in southern Illinois, Journal of Wildlife Management. 74(2):228235.

Breck SW, Wilson KR, Andersen DC. 2001. The demographic response of bank-dwelling beavers to flow regulation: a comparison on the Green and Yampa Rivers, Canadian Journal of Zoology. 79:1957-1964.

Collins T. 1976. Population characteristics and habitat relationships of beavers, (Castor canadensis) in Northwest Wyoming, Dissertation for the University of Wyoming, Department of Zoology and Physiology, pp. 172.

Fryxell JM. 2001. Habitat suitability and source-sink dynamics of beavers. Journal of Animal Ecology. 70:310-316. 
Fustec J, Lode T, LeJacques D, Cormier JP. 2001. Colonization, riparian habitat selection and home range size in a reintroduced population of European beavers in the Loire. Freshwater Biology. 46:1361-1371.

Gribb W, Harlow H. 2006. A survey of beaver location and habitat to model their distribution in Grand Teton National Park, Wyoming," UW-NPS 28 ${ }^{\text {th }}$ Annual Report 2004. NPS Research Center, pp. 31-37.

Jenkins SH. 1980. A size-distance relation in food selection by beavers. Ecology. 61:740-746.

Johnston DB, Cooper DJ, Hobbs NT. 2007, Elk browsing increases aboveground growth of water-stressed willows by modifying plant architecture. Oecologia. 154:467-478.

Johnston C, Naiman R. 1990. Browse selection by beaver: effects on riparian forest composition. Canadian Journal of Forest Research. 20:1036-1043.

McGinley MA, Whitham TG. 1985.Central place foraging by beavers (Castor Canadensis): a test of foraging predictions and the impact of selective feeding on the growth form of cottonwoods (Populus fremontii). Oecologia. 66:558-562.

Nelson NC. 2007. Hydrology and Geomorphology of the Snake River in Grand Teton National Park, Wyoming. Master Thesis. Utah State University.
Niaman RJ, Melillo JM, Hobbie JE. 1986. Ecosystem alteration of boreal forest streams by beaver (Castor Canadensis). Ecology. 67:12541269.

Nolet BA, Hoekstra A, Ottenheim MM. 1994. Selective foraging on woody species by the beaver Castor fiber, and its impact on a riparian willow forest. Biological Conservation. 70:117-128.

Olson R, Hubert WA. 1994. Beaver: Water Resources and Riparian Habitat Manager, University of Wyoming, Wyoming Cooperative Fish and Wildlife Research Unit.

Raffel N, Smith C, Cortright, Gatz AJ. 2009. Central place foraging by beavers (Castor canadensis) in a complex lake habitat. American Midland Naturalist. 162:62-73.

Smith D, Consolo-Murphy S, Phillips M, Crabtree R. 1996. Beaver Survey: Yellowstone National Park, Yellowstone National Park, National Park Service, YCR-NR-97-1.

Van Deelen TR, Pletscher DH. 1996. Dispersal characteristics of two year old beavers, Castor canadensis, in western Montana. Canadian Field Naturalist. 110:318-321. 